\title{
Effects of robot-assisted therapy on stroke rehabilitation in upper limbs: Systematic review and meta-analysis of the literature
}

\author{
Nahid Norouzi-Gheidari, MSc, OT; ${ }^{*}$ Philippe S. Archambault, PhD; Joyce Fung, PhD \\ School of Physical and Occupational Therapy, McGill University, Montreal, Quebec, Canada; Feil/Oberfeld/CRIR \\ Research Centre, Jewish Rehabilitation Hospital, Laval, Quebec, Canada
}

\begin{abstract}
We systematically reviewed and analyzed the literature to find randomized controlled trials (RCTs) that employed robotic devices in upper-limb rehabilitation of people with stroke. Out of 574 studies, 12 matching the selection criteria were found. The Fugl-Meyer, Functional Independence Measure, Motor Power Scale, and Motor Status Scale outcome measures from the selected RCTs were pooled together, and the corresponding effect sizes were estimated. We found that when the duration/intensity of conventional therapy (CT) is matched with that of the robot-assisted therapy (RT), no difference exists between the intensive CT and RT groups in terms of motor recovery, activities of daily living, strength, and motor control. However, depending on the stage of recovery, extra sessions of RT in addition to regular CT are more beneficial than regular CT alone in motor recovery of the hemiparetic shoulder and elbow of patients with stroke; gains are similar to those that have been observed in intensive CT.
\end{abstract}

Key words: activities of daily living, cerebrovascular accident, conventional therapy, Fugl-Meyer, Functional Independence Measure, intensive therapy, Motor Power Scale, Motor Status Scale, PEDro, randomized controlled trial.

\section{INTRODUCTION}

According to the World Health Organization, a stroke, also known as a cerebrovascular accident (CVA), is a sudden ischemic or hemorrhagic interruption in the blood flow supplying oxygen and nutrients to brain tissue. This event results in brain cell death and, conse- quently, partial loss of neurological function [1]. The occurrence of strokes has been progressively increasing. Currently, stroke is "the leading cause of adult disability in Western countries" [2] and one of the most common causes of death in the world [3]. The majority of people with stroke live with long-term disabilities leading to serious social and economic impacts. It is estimated that the direct and indirect cost of stroke care for the 6.5 million people living with the disability in the United States [4] was $\$ 73.7$ billion for 2010 [5]. According to "Tracking Heart Disease and Stroke in Canada” for 2009, stroke and heart diseases cost more than $\$ 22.2$ billion annually [6]. These numbers will continue to rise as the population ages and people live longer.

\footnotetext{
Abbreviations: ADL $=$ activities of daily living, $\mathrm{CI}=$ confidence interval, $\mathrm{CT}=$ conventional therapy, CVA = cerebrovascular accident, F-M = Fugl-Meyer, FIM = Functional Independence Measure, MeSH = Medical Subject Headings, MPS = Motor Power Scale, MSS = Motor Status Scale, PEDro = Physiotherapy Evidence Database, RCT = randomized controlled trial, RT = robot-assisted therapy, SMD = standardized mean difference, UL = upper limb.

*Address all correspondence to Nahid Norouzi-Gheidari, MSc, OT; School of Physical and Occupational Therapy, McGill University, 3654 Prom Sir William Osler, Montreal, Quebec, Canada, H3G 1Y5; 514-398-4500; fax: 514-3986360. Email: nahid.norouzi@mail.mcgill.ca http://dx.doi.org/10.1682/JRRD.2010.10.0210
} 
Depending on the magnitude and severity of the problem, people with stroke experience a variety of motor, sensory, and cognitive disabilities. A majority of patients have impaired upper-limb (UL) motor function following stroke and have difficulty in independently performing activities of daily living (ADL) [7-8]. Therefore, one of the challenging aspects of stroke rehabilitation is UL intervention. Studies have shown that only 6 to 10 percent of people with stroke who have severe paralysis achieve a full recovery by 6 months [9], and only 18 percent of them regain full UL function [10]. While the initial degree of stroke and paresis severity is a good predictor of UL function recovery [7,11-12], task-specific, high-intensity exercises in an active, functional, and highly repetitive manner over a large number of trials have been shown to enhance motor recovery, even in chronic stages of stroke [13]. Studies on the doseresponse relationship in stroke rehabilitation have shown that more intensive therapy is associated with enhanced rate of motor recovery; additionally, no ceiling effect for intensity of therapy has been observed [14-16]. Despite these findings, traditional therapies are still not delivered more intensively or frequently, often because of cost and labor limitations [17]. In addition, traditional "hands-on" interventions can, at times, result in repetitive strain injuries and excessive fatigue for therapists, thus leading to possible failure in delivery of highly intensive and repetitive training [18]. Moreover, major intra- and interindividual variability exists in the application of manual therapy, leading to inconsistent outcomes.

One of the novel and rapidly expanding technologies in poststroke rehabilitation for enhancing the recovery process and facilitating the restoration of function is robot-assisted therapy (RT). Rehabilitation robotics has some advantages over conventional treatment approaches. Advanced and intelligent robotic devices are able to provide consistent training and to measure performance with high reliability and accuracy [19]. Most importantly, robots may allow patients to train more independently and with less supervision from a therapist [20].

Compared with the research and development in conventional therapy (CT) techniques, the cost, effort, and time required for the research and development in rehabilitation robotics are significantly higher. Therefore, an important element in further development of therapeutic robots and RT programs is determining whether RT is more effective than $\mathrm{CT}$, based on the scientific evidence extracted from the literature. A systematic review is a rig- orous methodology for gathering, synthesizing, and evaluating available scientific evidence [21]. Therefore, the main objective of this article was to systematically analyze the literature to find evidence regarding the effectiveness of RT compared with CT in improving motor recovery and functional abilities of the paretic UL of patients with stroke. The following question presents the goal of this review in PICO (population, intervention, comparison, and outcome) format: "In poststroke individuals, does RT, as compared with CT, improve UL motor recovery and functional ability?”

\section{METHODS}

\section{Search Strategy}

Eleven scientific databases were systematically searched through their online search engines; these databases were MEDLINE (Medical Literature Analysis and Retrieval System Online; 1947 to July 2, 2010), CINAHL (Cumulative Index to Nursing and Allied Health Literature; 1982 to July 2, 2010), EMBASE (Excerpta Medica Database; 1947 to July 2, 2010), Cochrane CENTRAL (Central Register of Controlled Trials; Issue 3, July 2010), Cochrane Database of Systematic Reviews (Issue 7, July 2010), REHABDATA (Disability and Rehabilitation Literature Database; July 2, 2010), OTseeker (Occupational Therapy Systematic Evaluation of Evidence; last updated May 28, 2010), DARE (Database of Abstracts of Reviews of Effects; July 2, 2010), Physiotherapy Evidence Database (PEDro) (July 2, 2010), AMED (Allied and Complementary Medicine Database; 1985 to July 2, 2010), and PsycINFO (Psychological Information Database; 1967 to July 2, 2010). No start date limit was set on the search criteria of the databases, but the end date was the first week of July 2010.

The following key words were used in the searches and the corresponding Medical Subject Headings (MeSH) terms were selected and "exploded" during the search. The general search strategy was as follows:

- Search 1: Cerebrovascular Accident, Cerebral Vascular Accident, CVA, Stroke* (combined by OR operator).

- Search 2: Hemiplegia, Hemiparesis, Paresis, Hemip* (combined by OR operator).

- Search 3: Robotics, Robot* (combined by OR operator).

- Search 4: Upper Extremit*, Upper Limb*, Arm* (combined by OR operator). 
- Final Search: ((Search 1 OR Search 2) AND (Search 3 AND Search 4)).

In addition to the database searches, related reviews found during the search were examined and related publications included in the search results.

\section{MeSH Terms Definition}

Stroke is defined as "A group of pathological conditions characterized by sudden, non-convulsive loss of neurological function due to BRAIN ISCHEMIA or INTRACRANIAL HEMORRHAGES. Stroke is classified by the type of tissue NECROSIS, such as the anatomic location, vasculature involved, etiology, age of the affected individual, and hemorrhagic vs. non-hemorrhagic nature." (PubMed MEDLINE: MeSH database, 2008).

Robotics is defined as "The application of electronic, computerized control systems to mechanical devices designed to perform human functions. Formerly restricted to industry, but nowadays applied to artificial organs controlled by bionic (bioelectronic) devices, like automated insulin pumps and other prostheses." (PubMed MEDLINE: MeSH database, 1987).

Upper Extremity is defined as "The region of the upper limb in animals, extending from the deltoid region to the HAND, and including the ARM; AXILLA; and SHOULDER.” (PubMed MEDLINE: MeSH database, 2003).

\section{Study Selection Criteria}

The titles and abstracts of the studies found in the search were read independently by two of the reviewers. Based on the following criteria, suitable studies were included for the review. The reviewers had regular meetings about their findings, and in case of disagreement between the two reviewers, the third reviewer was consulted.

The inclusion criteria were-

- Participants were adult patients with stroke.

- Robot was used in the experimental protocol.

- RT was aimed at motor recovery, function, or control of the UL.

- Relevant outcomes measuring functional or motor recovery of the UL were used.

- Study was a randomized controlled trial (RCT).

- Control group received CT (either standard/usual care or intensive).

- Article was published in a peer-reviewed journal.
The exclusion criteria were-

- Studies that only compared two different RT techniques or devices.

- Robotic device was not used as a therapeutic tool.

- Pre-Post design studies.

The searches were not limited to the English language; articles published in languages other than English were examined by using their English abstracts or online translated versions of their abstracts.

\section{Methodological Quality Assessment}

The methodological quality of the chosen RCTs was evaluated using the PEDro scale [22]. Therapists and technicians who administer and supervise RT and CT know which subjects belong to the RT group and which ones to the CT group and are well aware of any assistance from the robotic device during the experimental sessions; therefore, it is very difficult in these studies to have a blinded therapist. In some studies, control groups were exposed to the robotic device in its passive mode (not assisting the patient), but even in these cases, nonassistance from the robot cannot be hidden from the person providing the intervention. Therefore, while the maximum score for the PEDro scale is 10, as the therapists and technicians providing the intervention cannot be blinded, the maximum possible score for the PEDro scale in this case is 9. For this reason, studies with PEDro scores higher than 5 were considered of high quality in this review.

\section{Data Extraction}

The selected publications were reviewed and the following information was extracted from them:

- Descriptive information about subjects in the experimental and control groups: age, sex, number of subjects, stroke type, time from stroke onset, inclusion and exclusion criteria.

- Outcome measures: outcomes, mean and standard deviation of the changes in the outcome measures postintervention.

- Intervention information in both groups: type of robot, intervention methodology, duration of the interventions.

- Statistically significant differences in outcome measures between RT and CT groups reported in the studies.

\section{Data Analysis}

Two outcome measures were selected for the analysis of motor and functional recovery of patients with stroke 
after RT in this review. The Fugl-Meyer (F-M) assessment [23-24] is a performance-based motor impairment index that measures motor recovery poststroke. The F-M UL motor score is commonly used as the main outcome measure in rehabilitation robotics research. The Functional Independence Measure (FIM) [25] is a disability scale commonly used in RT research to assess abilities for ADL. Therefore, the primary outcome measures of interest for statistical analysis using data pooling were the UL section of the F-M and the FIM. The statistical information about the changes in the F-M and FIM scores between admission and discharge were extracted, if available, or estimated from the selected RCTs. The effect size of each study was determined, and all of them were pooled together for calculating the summary effect size. In addition, 95 percent confidence intervals (CIs) were calculated. For this meta-analysis, we used Cochrane RevMan (version 5) software (The Cochrane Collaboration/The Nordic Cochrane Centre; Copenhagen, Denmark).

In addition, when available, Motor Power Scale (MPS) values, which measure strength in proximal muscles of the UL, and Motor Status Scale (MSS) values, which measure isolated movements of the UL, were pooled together.

\section{RESULTS}

Figure 1 summarizes the selection process of the RCTs included in this review. From the systematic literature search, 574 records were retrieved from all the databases mentioned (286 records from EMBASE, MEDLINE, PsycINFO, and AMED after automatic removal of duplicate records by the Ovid search engine, 85 from CINAHL, 32 from the Cochrane databases, 3 from DARE, 30 from OTseeker, 100 from REHABDATA, and 38 from PEDro). By screening the titles and abstracts of these records, we selected only 44 relevant studies for further detailed review. Out of these 44 studies, 4 RCTs were excluded because RT groups were compared with control groups that received treatments other than CT (Table A1 in the Appendix, available online only), 14 of them were review studies (Table $\mathbf{A 2}$ in the Appendix, available online only), 8 did not meet the inclusion-exclusion criteria (Table A3 in the Appendix, available online only), and 6 presented preliminary results or were related to the included RCTs (Table A4 in the Appendix, available online only).
Based on the inclusion-exclusion criteria, 11 RCTs (plus 1 follow-up study [26] of another included RCT [27]) were qualified for inclusion in this review. A summary of the included studies is shown in Table $\mathbf{1}$ with information about the participants, the robotic device, and the outcome measures that is of particular interest for this review.

The participants with stroke in these RCTs ranged from acute to chronic at the time of admission to the experiments. Six robotic instruments were used in these RCTs: REHAROB [28], T-WREX [29], ARM-Guide [30], MIME [31-32], NeReBot [33], and MIT-Manus [26-27,34-37]. Most of the studies (and most robots) focused on the restoration of proximal UL function. One study compared three RT groups with CT to investigate the effect of bilateral RT [31]; in our analysis, only the data from the unilateral RT group has been used. The other RCTs also focused on unilateral RT (except one [32] that incorporated bilateral therapy in addition to unilateral therapy inside the RT program).

\section{Summary of Robotic Devices}

Among the wide variety of robotic devices that have been developed and used for stroke rehabilitation, those employed in the selected RCTs were the following:

- MIT-MANUS shoulder and elbow module is a twodegree-of-freedom robot allowing patients to perform reaching movements in the horizontal plane [38]. The wrist module of MIT-MANUS is a three-degree-offreedom robotic device allowing abduction-adduction, flexion-extension, and pronation-supination [39]. The system also includes an antigravity module for vertical movements and a grasp-hand module for closing and opening movements [34]. The device provides assistive or resistive forces as well as a passive mode, enabling patients to train their shoulder, elbow, and wrist.

- MIME, or "Mirror Image Movement Enabler," is a robotic device with six degrees of freedom [32]. MIME applies assistance or resistance forces to the patient's paretic forearm. In bimanual mode, the robot helps patients move their affected arm in a pattern that mirrors that of the less affected arm.

- ARM-Guide, or "Assisted Rehabilitation and Measurement Guide,” is a four-degree-of-freedom robotic device developed by Kahn et al. [40] that allows patients with stroke to reach along a linear track.

- T-WREX, or "Therapy Wilmington Robotic Exoskeleton," was developed at the University of CaliforniaIrvine. T-WREX is a five-degree-of-freedom passive 


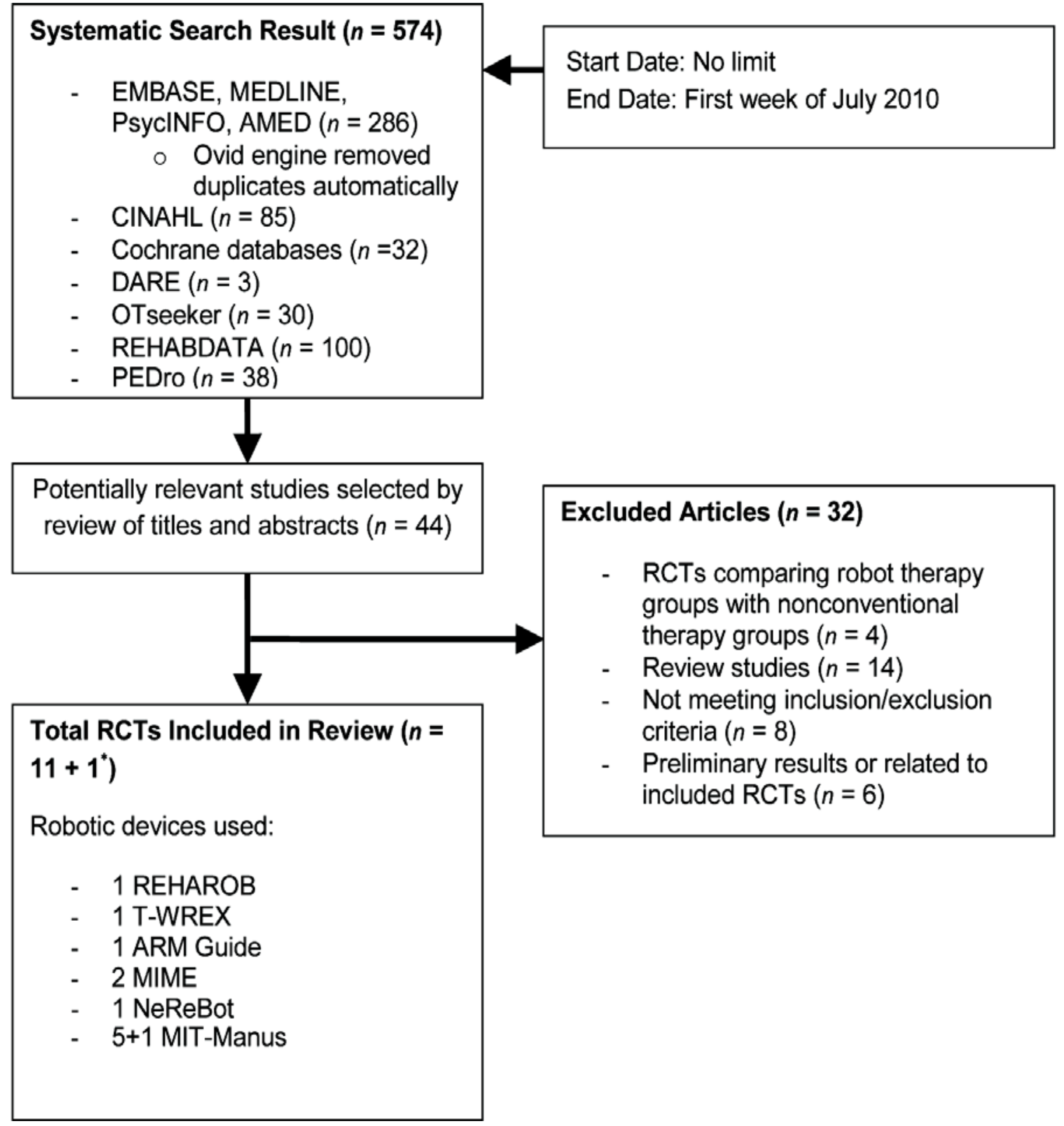

Figure 1.

Flow diagram of selection process of randomized controlled trials (RCTs) included in this review. "One study is follow-up of another included RCT.

antigravity orthosis with a computer workstation [41]. This device allows patients to exercise in a more functional way.

- NeReBot or "NEuro REhabilitation Robot," [42] is a three-degree-of-freedom robot, designed and built at Padova University. The robot system comprises a set of three nylon cables attached to a rigid orthosis, which is independently controlled by three direct-current motors.

\section{Methodological Quality Assessment}

The results of the methodological quality assessment using the PEDro scale are summarized in Table 2. The PEDro scores ranged from 2 to 7. All studies were considered high quality except Fazekas et al. [28], which had a PEDro score of 2; as a result of the low PEDro score and also because the statistical information for the "between group comparison" and "point estimates and variability” was not included, this study was excluded 
JRRD, Volume 49, Number 4, 2012

Table 1.

Characteristics of selected randomized controlled trials.

\begin{tabular}{|c|c|c|c|c|c|c|c|c|c|}
\hline \multirow[t]{2}{*}{ Study } & \multicolumn{2}{|c|}{$N($ Sex $)$} & \multicolumn{2}{|c|}{$\begin{array}{c}\text { Age (yr) } \\
\text { Mean } \pm \text { SD (Range) }\end{array}$} & \multicolumn{2}{|c|}{$\begin{array}{c}\text { Months/[weeks]/“day" } \\
\text { Poststroke } \\
\text { Mean } \pm \text { SD or (Range) }\end{array}$} & \multirow[t]{2}{*}{$\begin{array}{l}\text { Stroke Stage } \\
\text { at Admission }\end{array}$} & \multirow[t]{2}{*}{$\begin{array}{l}\text { Robotic } \\
\text { Device }\end{array}$} & \multirow{2}{*}{$\begin{array}{c}\text { Outcome } \\
\text { Measures of } \\
\text { Interest }\end{array}$} \\
\hline & $\overline{\mathrm{RT}}(\mathrm{M} / \mathrm{F})$ & $\mathrm{CT}(\mathrm{M} / \mathrm{F})$ & RT & CT & RT & $\mathrm{CT}$ & & & \\
\hline Kahn et al. [3] & $10(4 / 6)$ & $9(7 / 2)$ & $55.6 \pm 12.2$ & $55.9 \pm 12.3$ & $75.8 \pm 45.5$ & $103.1 \pm 48.2$ & Chronic & ARM Guide & $\begin{array}{l}\text { Ch-McM } \\
\text { (arm) }\end{array}$ \\
\hline Lum et al. [4] & $13(12 / 1)$ & $14(8 / 6)$ & $63.2 \pm 3.6$ & $65.9 \pm 2.4$ & $30.2 \pm 6.2$ & $28.8 \pm 6.3$ & Chronic & MIME & $\begin{array}{l}\text { F-M (UL), } \\
\text { FIM (self- } \\
\text { care) }\end{array}$ \\
\hline Masiero et al. [6] & $17(10 / 7)$ & $18(11 / 7)$ & $63.4 \pm 11.8$ & $68.8 \pm 10.5$ & {$[\leq 1$ week] } & {$[\leq 1$ week $]$} & Acute & NeReBot & $\begin{array}{l}\text { F-M (s/e/c, } \\
\text { w/h), FIM } \\
\text { (self-care) }\end{array}$ \\
\hline Aisen et al. [7] ${ }^{\S}$ & $10(5 / 5)$ & $10(6 / 4)$ & $58.5 \pm 8.3$ & $63.3 \pm 10.6$ & {$[2.8 H 1.1] \mathrm{wk}$} & [3.3H.2] $\mathrm{wk}$ & Acute & MIT-Manus & $\begin{array}{l}\text { F-M (UL), } \\
\text { FIM (self- } \\
\text { care), MSS, } \\
\text { MPS }\end{array}$ \\
\hline Volpe et al. [9] & $30(16 / 14)$ & $26(14 / 12)$ & $62 \pm 11$ & $67 \pm 10.2$ & 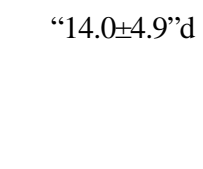 & “15.8土6.6”d & Acute & MIT-Manus & $\begin{array}{l}\text { F-M (s/e/c, } \\
\text { w/h), FIM } \\
\text { (motor), } \\
\text { MSS, MPS }\end{array}$ \\
\hline Volpe et al. [10] & $11(8 / 3)$ & $10(7 / 3)$ & $62 \pm 3$ & $60 \pm 3$ & {$[35 \pm 7] \mathrm{wk}$} & {$[40 \pm 11] \mathrm{wk}$} & Chronic & MIT-Manus & $\begin{array}{l}\text { F-M (s/e/c, } \\
\text { w/h), MPS }\end{array}$ \\
\hline Rabadi et al. [11] & $10(5 / 5)$ & $10(5 / 5)$ & $79.5 \pm 6.2$ & $67.8 \pm 12.7$ & 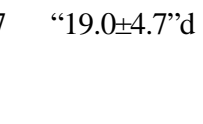 & “22.5+18.2”d & Acute & MIT-Manus & $\begin{array}{l}\text { F-M (UL), } \\
\text { FIM (motor), } \\
\text { MSS, MPS }\end{array}$ \\
\hline Lo et al. [12] & $49(47 / 2)$ & $\begin{array}{l}50(48 / 2) \\
28(27 / 1)\end{array}$ & $\begin{array}{l}66 \pm 11 \\
\quad(44-95)\end{array}$ & $\begin{array}{c}64 \pm 11 \\
(28-86) \\
63 \pm 12 \\
(42-88)\end{array}$ & $\begin{array}{l}3.6 \pm 4.0 \\
(0.6-19.8)\end{array}$ & $\begin{array}{c}4.8 \pm 4.0 \\
(0.5-15.7) \\
6.2 \pm 5.0 \\
(0.5-23.6)\end{array}$ & Chronic & MIT-Manus & F-M (UL) \\
\hline
\end{tabular}


Table 1. (cont)

Characteristics of selected randomized controlled trials.

*13 stroke and 2 TBI.

${ }^{\dagger} 9$ stroke and 6 TBI.

¥3 RT groups (top to bottom): robot-combined, robot-unilateral, robot-bilateral.

${ }^{\S}$ Volpe et al. [8] is follow-up study of Aisen et al [7].

I2 CT groups (top to bottom): intensive comparison therapy and usual care.

1. Fazekas G, Horvath M, Troznai T, Toth A. Robot-mediated upper limb physiotherapy for patients with spastic hemiparesis: a preliminary study. J Rehabil Med. 2007;39(7):580-82. [Stiftelsen Rehabiliteringsinformation].

2. Housman SJ, Scott KM, Reinkensmeyer DJ. A randomized controlled trial of gravity-supported, computer-enhanced arm exercise for individuals with severe hemiparesis. Neurorehabil Neural Repair. 2009;23(5):505-14.

3. Kahn LE, Zygman ML, Rymer WZ, Reinkensmeyer DJ. Robot-assisted reaching exercise promotes arm movement recovery in chronic hemiparetic stroke: a randomized controlled pilot study. J Neuroeng Rehabil. 2006;3(1):12.

4. Lum PS, Burgar CG, Shor PC, Majmundar M, Van der Loos M. Robot-assisted movement training compared with conventional therapy techniques for the rehabilitation of upper-limb motor function after stroke. Arch Phys Med Rehabil. 2002;83(7):952-59.

5. Lum PS, Burgar CG, Van der Loos M, Shor PC, Majmundar M, Yap R. MIME robotic device for upper-limb neurorehabilitation in subacute stroke subjects: A follow-up study. J Rehabil Res Dev. 2006;43(5):631-42.

6. Masiero S, Celia A, Rosati G, Armani M. Robotic-assisted rehabilitation of the upper limb after acute stroke. Arch Phys Med Rehabil. 2007;88(2):142-49.

7. Aisen ML, Krebs HI, Hogan N, McDowell F, Volpe BT. The effect of robot-assisted therapy and rehabilitative training on motor recovery following stroke. Arch Neurol. 1997;54(4):443-46.

8. Volpe BT, Krebs HI, Hogan N, Edelsteinn L, Diels CM, Aisen ML. Robot training enhanced motor outcome in patients with stroke maintained over 3 years. Neurology. 1999;53(8):1874-76.

9. Volpe BT, Krebs HI, Hogan N, Edelstein OTR L, Diels C, Aisen M. A novel approach to stroke rehabilitation: robot-aided sensorimotor stimulation. Neurology. 2000;54(10):1938-44.

10. Volpe BT, Lynch D, Rykman-Berland A, Ferraro M, Galgano M, Hogan N, Krebs HI. Intensive sensorimotor arm training mediated by therapist or robot improves hemiparesis in patients with chronic stroke. Neurorehabil Neural Repair. 2008;22(3):305-10.

11. Rabadi MH, Galgano M, Lynch D, Akerman M, Lesser M, Volpe BT. A pilot study of activity-based therapy in the arm motor recovery post stroke: a randomized controlled trial. Clin Rehabil. 2008;22(12):1071-82.

12. Lo AC, Guarino PD, Richards LG, Haselkorn JK, Wittenberg GF, Federman DG, Ringer RJ, Wagner TH, Krebs HI, Volpe BT, Bever CT Jr, Bravata DM, Duncan PW, Corn BH, Maffucci AD, Nadeau SE, Conroy SS, Powell JM, Huang GD, Peduzzi P. Robot-assisted therapy for long-term upper-limb impairment after stroke. N Engl J Med. 2010;362(19):1772-83.

$\mathrm{c}=$ coordination, Ch-McM = Chedoke-McMaster, CT = conventional therapy, e = elbow, F = female, FIM = Functional Independence Measure, F-M = Fugl-Meyer, $\mathrm{M}=$ male, MPS = Motor Power Scale, MSS = Motor Status Scale, RT = robot-assisted therapy, SD = standard deviation, $\mathrm{s}=$ shoulder, TBI = traumatic brain injury, $\mathrm{UL}=$ upper limb, $\mathrm{w} / \mathrm{h}=$ wrist $/ \mathrm{hand}$.

from further analysis. In two of the studies, some of the baseline values were not comparable between the groups. In Lum et al. [31], three robotic groups were compared with the control group; the baseline values of the Modified Ashworth Scale and MSS Synergy Scale for two of the robotic groups were different, and therefore, between-groups comparison was not performed for these two outcome measures. In the second study, Rabadi et al. [35], even though several baseline values were different between the groups, the confounding effects of baseline difference in age, stroke type, and some of the outcome measures were adjusted during the statistical analysis.

\section{Quantitative Analysis}

In order to compare the motor recovery in patients with stroke between RT and CT groups, nine of the selected studies used changes in F-M score, while one study used the Chedoke-McMaster measure for quantifying motor recovery [30]; this study has therefore been excluded from the following analyses. In addition, changes in MPS and MSS scores were used in some of the studies [27,31,35-37]. Six of the studies used changes in the FIM to assess improvement in functional performance $[27,31-33,35,37]$. Therefore, the focus of the quantitative analysis was on the F-M, FIM, MPS, and MSS measures.

When the effectiveness of RT versus CT is compared, two factors may affect the outcome measures of interest. The first factor is the duration/intensity of the therapy in the RT and CT groups (whether they are the same or the RT group received additional therapy) and the second one is the stage of stroke recovery (acute/subacute or chronic) of the participants in the studies. Table 3 categorizes the studies based on these two factors. Matching of duration/intensity in RT and CT groups for the studies shown in the first column of Table 3 refers to the same treatment time per session and the same total number of sessions; in two of the studies [34-35] the same form of treatment was administered, and in one study [34], even the number of movements between the 
JRRD, Volume 49, Number 4, 2012

Table 2.

Quality assessment of selected randomized controlled trials using Physiotherapy Evidence Database (PEDro) scale: higher score implies higher quality.

\begin{tabular}{|c|c|c|c|c|c|c|c|c|c|c|c|c|}
\hline Study & $\begin{array}{c}\text { Eligibility } \\
\text { Criteria }\end{array}$ & $\begin{array}{c}\text { Random } \\
\text { Allocation }\end{array}$ & $\begin{array}{l}\text { Concealed } \\
\text { Allocation }\end{array}$ & $\begin{array}{c}\text { Baseline } \\
\text { Comparability }\end{array}$ & $\begin{array}{c}\text { Blind } \\
\text { Subjects }\end{array}$ & $\begin{array}{c}\text { Blind } \\
\text { Therapists }\end{array}$ & $\begin{array}{c}\text { Blind } \\
\text { Assessors }\end{array}$ & $\begin{array}{c}\text { Adequate } \\
\text { Follow-Up } \\
\text { (Drop-out } \\
\text { rate) }\end{array}$ & $\begin{array}{c}\text { Intention- } \\
\text { to-Treat } \\
\text { Analysis }\end{array}$ & $\begin{array}{c}\text { Between- } \\
\text { Group } \\
\text { Comparisons }\end{array}$ & $\begin{array}{l}\text { Point } \\
\text { Estimates } \\
\text { and } \\
\text { Variability }\end{array}$ & $\begin{array}{c}\text { PEDro } \\
\text { Score }\end{array}$ \\
\hline Fazekas et al. [1] & No & Yes & No & No & No & No & Yes & No & No & No & No & 2 \\
\hline $\begin{array}{l}\text { Housman et al. } \\
\text { [2] }\end{array}$ & Yes & Yes & No & Yes & No & No & Yes & No & No & Yes & Yes & 5 \\
\hline Kahn et al. [3] & Yes & Yes & No & Yes & No & No & Yes & No & No & Yes & Yes & 5 \\
\hline Lum et al. [4] & Yes & Yes & No & Yes & No & No & Yes & Yes & No & Yes & Yes & 6 \\
\hline Lum et al. [5] & Yes & Yes & No & No & No & No & Yes & Yes & No & Yes & Yes & 5 \\
\hline $\begin{array}{l}\text { Masiero et al. } \\
\text { [6] }\end{array}$ & Yes & Yes & No & Yes & No & No & Yes & Yes & No & Yes & Yes & 6 \\
\hline $\begin{array}{l}\text { Aisen et al. [7] } \\
\& \text { Volpe et al. } \\
\text { [8]* }\end{array}$ & No & Yes & No & Yes & Yes & No & Yes & No & No & Yes & Yes & 6 \\
\hline Volpe et al. [9] & Yes & Yes & No & Yes & Yes & No & Yes & Yes & No & Yes & Yes & 7 \\
\hline Volpe et al. [10] & Yes & Yes & No & Yes & No & No & Yes & Yes & No & Yes & Yes & 6 \\
\hline $\begin{array}{l}\text { Rabadi et al. } \\
\text { [11] }\end{array}$ & Yes & Yes & Yes & No & No & No & Yes & Yes & No & Yes & Yes & 6 \\
\hline Lo et al. [12] & Yes & Yes & No & Yes & No & No & Yes & Yes & No & Yes & Yes & 6 \\
\hline
\end{tabular}

"Volpe et al. [8] is follow-up study of Aisen et al. [7].

1. Fazekas G, Horvath M, Troznai T, Toth A. Robot-mediated upper limb physiotherapy for patients with spastic hemiparesis: a preliminary study. J Rehabil Med. 2007;39(7):580-82. [Stiftelsen Rehabiliteringsinformation].

2. Housman SJ, Scott KM, Reinkensmeyer DJ. A randomized controlled trial of gravity-supported, computer-enhanced arm exercise for individuals with severe hemiparesis. Neurorehabil Neural Repair. 2009;23(5):505-14.

3. Kahn LE, Zygman ML, Rymer WZ, Reinkensmeyer DJ. Robot-assisted reaching exercise promotes arm movement recovery in chronic hemiparetic stroke: a randomized controlled pilot study. J Neuroeng Rehabil. 2006;3(1):12.

4. Lum PS, Burgar CG, Shor PC, Majmundar M, Van der Loos M. Robot-assisted movement training compared with conventional therapy techniques for the rehabilitation of upper-limb motor function after stroke. Arch Phys Med Rehabil. 2002;83(7):952-59.

5. Lum PS, Burgar CG, Van der Loos M, Shor PC, Majmundar M, Yap R. MIME robotic device for upper-limb neurorehabilitation in subacute stroke subjects: A follow-up study. J Rehabil Res Dev. 2006;43(5):631-42.

6. Masiero S, Celia A, Rosati G, Armani M. Robotic-assisted rehabilitation of the upper limb after acute stroke. Arch Phys Med Rehabil. 2007;88(2):142-49.

7. Aisen ML, Krebs HI, Hogan N, McDowell F, Volpe BT. The effect of robot-assisted therapy and rehabilitative training on motor recovery following stroke. Arch Neurol. 1997;54(4):443-46.

8. Volpe BT, Krebs HI, Hogan N, Edelsteinn L, Diels CM, Aisen ML. Robot training enhanced motor outcome in patients with stroke maintained over 3 years. Neurology. 1999;53(8):1874-76.

9. Volpe BT, Krebs HI, Hogan N, Edelstein OTR L, Diels C, Aisen M. A novel approach to stroke rehabilitation: robot-aided sensorimotor stimulation. Neurology. 2000;54(10):1938-44.

10. Volpe BT, Lynch D, Rykman-Berland A, Ferraro M, Galgano M, Hogan N, Krebs HI. Intensive sensorimotor arm training mediated by therapist or robot improves hemiparesis in patients with chronic stroke. Neurorehabil Neural Repair. 2008;22(3):305-10.

11. Rabadi MH, Galgano M, Lynch D, Akerman M, Lesser M, Volpe BT. A pilot study of activity-based therapy in the arm motor recovery post stroke: a randomized controlled trial. Clin Rehabil. 2008;22(12):1071-82.

12. Lo AC, Guarino PD, Richards LG, Haselkorn JK, Wittenberg GF, Federman DG, Ringer RJ, Wagner TH, Krebs HI, Volpe BT, Bever CT Jr, Bravata DM, Duncan PW, Corn BH, Maffucci AD, Nadeau SE, Conroy SS, Powell JM, Huang GD, Peduzzi P. Robot-assisted therapy for long-term upper-limb impairment after stroke. N Engl J Med. 2010;362(19):1772-83. 
Table 3.

Study categorization based on two factors that affect outcome measures of interest.

\begin{tabular}{lll}
\hline \multirow{2}{*}{ Stroke Stage } & \multicolumn{2}{c}{ Duration/Intensity of RT vs CT } \\
\cline { 2 - 3 } & \multicolumn{1}{c}{ Same } & \multicolumn{1}{c}{ Additional } \\
\hline Acute/Subacute & Lum et al. [1] & Aisen et al. [7] \\
& Rabadi et al. [2] & Masiero et al. [8] \\
& & Volpe et al. [9] \\
Chronic & Housman et al. [3] & Lo et al. [4] \\
& Lo et al. [4] & \\
& Lum et al. [5] & \\
& Volpe et al. [6] & \\
\end{tabular}

1. Lum PS, Burgar CG, Van der Loos M, Shor PC, Majmundar M, Yap R. MIME robotic device for upper-limb neurorehabilitation in subacute stroke subjects: A follow-up study. J Rehabil Res Dev. 2006;43(5):631-42.

2. Rabadi MH, Galgano M, Lynch D, Akerman M, Lesser M, Volpe BT. A pilot study of activity-based therapy in the arm motor recovery post stroke: a randomized controlled trial. Clin Rehabil. 2008;22(12):1071-82.

3. Housman SJ, Scott KM, Reinkensmeyer DJ. A randomized controlled trial of gravity-supported, computer-enhanced arm exercise for individuals with severe hemiparesis. Neurorehabil Neural Repair. 2009;23(5):505-14.

4. Lo AC, Guarino PD, Richards LG, Haselkorn JK, Wittenberg GF, Federman DG, Ringer RJ, Wagner TH, Krebs HI, Volpe BT, Bever CT Jr, Bravata DM, Duncan PW, Corn BH, Maffucci AD, Nadeau SE, Conroy SS, Powell JM, Huang GD, Peduzzi P. Robot-assisted therapy for long-term upper-limb impairment after stroke. N Engl J Med. 2010;362(19):1772-83.

5. Lum PS, Burgar CG, Shor PC, Majmundar M, Van der Loos M. Robotassisted movement training compared with conventional therapy techniques for the rehabilitation of upper-limb motor function after stroke. Arch Phys Med Rehabil. 2002;83(7):952-59.

6. Volpe BT, Lynch D, Rykman-Berland A, Ferraro M, Galgano M, Hogan N, Krebs HI. Intensive sensorimotor arm training mediated by therapist or robot improves hemiparesis in patients with chronic stroke. Neurorehabil Neural Repair. 2008;22(3):305-10.

7. Aisen ML, Krebs HI, Hogan N, McDowell F, Volpe BT. The effect of robotassisted therapy and rehabilitative training on motor recovery following stroke. Arch Neurol. 1997;54(4):443-46.

8. Masiero S, Celia A, Rosati G, Armani M. Robotic-assisted rehabilitation of the upper limb after acute stroke. Arch Phys Med Rehabil. 2007;88(2):142-49.

9. Volpe BT, Krebs HI, Hogan N, Edelstein OTR L, Diels C, Aisen M. A novel approach to stroke rehabilitation: robot-aided sensorimotor stimulation. Neurology. 2000;54(10):1938-44.

$\mathrm{CT}=$ conventional therapy, $\mathrm{RT}=$ robot-assisted therapy.

RT and CT groups was matched. All these parameters are referred as "duration/intensity" in the text. The data pooling analyses were run independently for each factor since, to our knowledge, no two-way meta-analysis technique exists.

Since the selected RCTs used different robotic devices, methodology, and subscales of outcome measures, we used the random-effects technique in the following meta-analyses to consider the potential effect of heterogeneity, i.e., potential variability among the selected RCTs. Also, in studies in which the standard deviation or mean of change of the outcome measures of interest has not been directly reported, calculated or estimated values were used in the meta-analyses. For illustration of the meta-analyses results, we included forest plot graphics in which the location of the filled square, its width, and its size represent the mean of change in the outcome measure of interest between RT and CT, its 95 percent CI, and the weight of each study in that meta-analysis, respectively. The width of the diamond in a forest plot shows the 95 percent $\mathrm{CI}$ for the pooled results of the meta-analysis. A study weight in each meta-analysis is determined based on the mean, standard deviation, and number of subjects in that study compared with the other studies included in the meta-analysis.

\section{Fugl-Meyer Meta-Analysis}

In all the selected RCTs except one [30], the F-M measure was used for quantification of motor recovery. This study (Kahn et al. [30]) used the Chedoke-McMaster measure and therefore was not included in the F-M metaanalysis. Three of the studies measured the F-M UL Total score $[27,29,34]$, while the others reported the F-M Proximal (shoulder/elbow/coordination) and the F-M Distal (wrist/hand) scores separately [31-33,35-37]. The latter studies did not report any significant difference between the RT and CT groups in terms of change in the F-M Distal score. Therefore, in order to pool all the F-M measurements, we assumed that the changes in the F-M Total score were mostly due to changes in the F-M Proximal score. Based on this assumption, we pooled changes in the F-M Total and F-M Proximal together in this metaanalysis. In order to further remove any potential bias caused by this assumption, we used the standardized mean difference (SMD), rather than mean difference, to normalize the scales.

In order to compare the effectiveness of RT versus CT, we performed two separate meta-analyses. In the first meta-analysis, we formed two subgroups based on the comparability of the duration/intensity of the RT and CT (i.e., additional duration/intensity for the RT group or the same duration/intensity for RT and CT). The results are shown in Figure 2. One study (Lo et al. [34]) compared RT with two control groups (intensive CT that matched the duration/intensity of the RT and usual CT) and has therefore been included in both subgroups. The results show that when RT is used as additional therapy, the motor recovery in RT groups is significantly higher than CT groups ( $p=0.004)$, but when the CT duration/ intensity is matched with the RT, the gain is not statistically significant. 
In the second meta-analysis, two subgroups were also formed, based on the stroke recovery stage of the participants (i.e., acute/subacute or chronic). However, as shown in Figure 2, the comparability of the duration/ intensity of the RT and CT has a significant effect on the results. Therefore, meta-analyses were separately performed for the four factorial combinations in Table 3. The results are displayed in Figure 3 and reveal that in both early and late stages of stroke recovery when the duration/intensity of CT is matched with RT, motor recovery improvements are not statistically different between the two groups. However, the results do show that during the acute/subacute stage of stroke recovery, additional RT leads to significantly greater gains in F-M score than CT alone ( $p=0.01)$. We could not perform any meta-analysis on effect of additional RT during chronic stage because only one study was in this category (Lo et al. [34]). This study reported that gains were not statistically significantly different between additional RT and usual CT.

\section{Functional Independence Measure Meta-Analysis}

The FIM scale has two subsections: Motor (including self-care, sphincter control, mobility/transfer, and loco- motion) and Cognition (including communication and social cognition). FIM Total was measured in three of the RCTs [27,33,35], two of which reported the FIM Motor scores as well $[33,35]$. One study measured the FIM Motor (except for sphincter control) [37], and two studies measured FIM self-care and transfer [31-32]. Only three studies measured the changes in FIM Cognition and reported that these changes were not different between the RT and CT groups [33,35,37]. We therefore assumed that the changes in the FIM Total and FIM Motor (or its subscales) could be pooled together for the purpose of this meta-analysis. In order to further remove any potential bias caused by this assumption, we used the SMD rather than mean difference to normalize the scales. Similar to the F-M meta-analysis, the studies for the FIM metaanalysis were placed in subgroups based on the comparability of duration/intensity of RT and CT (additional duration/intensity for RT or the same duration/intensity).

Figure 4 shows the results of this meta-analysis. The statistics of the pooled results in both subgroups indicate that no statistically significant difference existed between RT and CT in terms of improvement in ADL, whether applying additional RT or not.

\begin{tabular}{|c|c|c|c|c|c|c|c|c|}
\hline \multirow{2}{*}{ Subgroup/Study } & \multicolumn{2}{|l|}{ RT } & \multicolumn{2}{|l|}{ CT } & \multirow{2}{*}{$\begin{array}{c}\text { Weight } \\
(\%)\end{array}$} & \multirow{2}{*}{$\begin{array}{c}\text { SMD IV, Random, } \\
95 \% \mathrm{Cl}\end{array}$} & \multirow{2}{*}{\multicolumn{2}{|c|}{$\begin{array}{c}\text { SMD IV, Random, } \\
95 \% \mathrm{Cl}\end{array}$}} \\
\hline & Mean \pm SD & Total & Mean \pm SD & Total & & & & \\
\hline \multicolumn{9}{|l|}{ Additional RT } \\
\hline Aisen et al. [27] & $14.1 \pm 9.7$ & 10 & $10.1 \pm 11.63$ & 10 & 12.8 & $0.36(-0.53$ to 1.24$)$ & & \\
\hline Lo et al. [34] & $1.11 \pm 5.05$ & 25 & $-1.06 \pm 5.2$ & 27 & 33.2 & $0.42(-0.13$ to & & \\
\hline Masiero et al. [33] & $12.8 \pm 5.5$ & 15 & $7.5 \pm 9.5$ & 15 & 18.4 & $0.66(-0.07$ to 1.40$)$ & & \\
\hline Volpe et al. [37] & $5.0 \pm 2.5$ & 30 & $4 \pm 2$ & 26 & 35.5 & $0.43(-0.10$ to 0.96$)$ & & \\
\hline Subtotal $(95 \% \mathrm{Cl})$ & - & 80 & - & 78 & 100.0 & $0.46(0.14$ to 0.78$)$ & & \\
\hline \multicolumn{9}{|c|}{ Same Duration/Intensity Therapy ${ }^{\dagger}$} \\
\hline Housman et al. [29] & $3.3 \pm 2.4$ & 14 & $2.2 \pm 2.6$ & 14 & 15.1 & $0.43(-0.32$ to 1.18$)$ & & \\
\hline Lo et al. [34] & $3.87 \pm 2.78$ & 47 & $4.01 \pm 7.19$ & 46 & 39.7 & $-0.03(-0.43$ to 0.38$)$ & & - \\
\hline Lum et al. [32] & $3.3 \pm 2.5$ & 13 & $1.6 \pm 1.1$ & 14 & 13.7 & $0.86(0.06$ to 1.65$)$ & & \\
\hline Lum et al. [31] & $4.3 \pm 4.2$ & 9 & $2.5 \pm 1.5$ & 6 & 8.2 & $0.50(-0.56$ to 1.55$)$ & & \\
\hline Rabadi et al. [35] & $2.53 \pm 4.25$ & 10 & $3.55 \pm 4.62$ & 10 & 11.4 & $-0.22(-1.10$ to 0.66$)$ & & \\
\hline Volpe & $2.94 \pm 6.63$ & 11 & $3.67 \pm 5.38$ & 10 & 11.9 & $-0.12(-0.97$ & & \\
\hline Subtotal $(95 \% \mathrm{Cl})$ & - & 104 & - & 100 & 100.0 & $0.17(-0.14$ to 0.48$)$ & & \\
\hline \multicolumn{7}{|c|}{$\begin{array}{l}\text { "Heterogeneity: } I^{2}=0.00 ; X^{2}=0.38, d f=3(p=0.94) ; I^{2}=0 \% \text {. Test for overall effect: } Z=2.85(p= \\
0.004) \text {. } \\
{ }^{\dagger} \text { Heterogeneity: } T^{2}=0.02 ; X^{2}=5.74, d f=5(p=0.33) ; I^{2}=13 \% \text {. Test for overall effect: } Z=1.09(p= \\
0.28) \text {. }\end{array}$} & $\begin{array}{cc}-1 & -0.5 \\
\text { Favors } \mathrm{CT}\end{array}$ & $\begin{array}{ccc}0 & 0.5 & 1 \\
& \text { Favors RT }\end{array}$ \\
\hline
\end{tabular}

Figure 2.

Results of changes in Fugl-Meyer (F-M) score between robot-assisted therapy (RT) and conventional therapy (CT). Two meta-analyses were performed based on relative duration/intensity of RT and CT. In these meta-analyses, standardized mean difference (SMD) of F-M Total score in Aisen et al., 1997 [27], Housman et al., 2009 [29], and Lo et al., 2010 [34] and SMD of F-M Proximal score in rest of studies were pooled together. $\mathrm{Cl}=$ confidence interval, SD = standard deviation. 
NOROUZI-GHEIDARI et al. Meta-analysis of upper-limb rehabilitation robotics in stroke

\begin{tabular}{|c|c|c|c|c|c|c|c|c|}
\hline Subgroup/Study & \multicolumn{2}{|l|}{$\mathbf{R T}$} & \multicolumn{2}{|l|}{ CT } & $\begin{array}{l}\text { Weight } \\
(\%)\end{array}$ & $\begin{array}{c}\text { SMD IV, Random, } \\
95 \% \mathrm{Cl}\end{array}$ & \multicolumn{2}{|c|}{$\begin{array}{c}\text { SMD IV, Random, } \\
95 \% \mathrm{Cl}\end{array}$} \\
\hline \multicolumn{9}{|c|}{ Same Duration/Intensity Therapy: Acute/Subacute } \\
\hline Lum et al. [31] & $4.3 \pm 4.2$ & 9 & $2.5 \pm 1.5$ & 6 & 41.5 & $0.50(-0.56$ to 1.55$)$ & & \\
\hline Rabadi et al. [35] & $2.53 \pm 4.25$ & 10 & $3.55 \pm 4.62$ & 10 & 58.5 & $-0.22(-1.10$ to 0.66$)$ & & \\
\hline \multirow{2}{*}{\multicolumn{9}{|c|}{ Same Duration/Intensity Therapy: Chronic ${ }^{\dagger}$}} \\
\hline & & & & & & & & \\
\hline Housman et al. [29] & $3.3 \pm 2.4$ & 14 & $2.2 \pm 2.6$ & 14 & 21.2 & $0.43(-0.32$ to 1 & & \\
\hline & $3.87 \pm 2.78$ & 47 & $4.01 \pm 7.19$ & 46 & 41.8 & 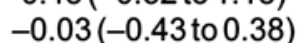 & & \\
\hline Lum et al. [32] & $3.3 \pm 2.5$ & 13 & $1.6 \pm 1.1$ & 14 & 19.6 & $0.86(0.06$ to 1.65$)$ & & \\
\hline Volpe et al. [36] & $2.94 \pm 6.63$ & 11 & $3.67 \pm 5.38$ & 10 & 17.5 & $-0.12(-0.97$ to 0.74$)$ & & \\
\hline Subtotal $(95 \% \mathrm{Cl})$ & - & 85 & - & 84 & 100.0 & $0.23(-0.19$ to 0.64$)$ & & \\
\hline \multicolumn{9}{|c|}{ Additional RT: Acute/Subacute ${ }^{\ddagger}$} \\
\hline Aisen et al. [27] & $14.1 \pm 9.7$ & 10 & $10.1 \pm 11.6$ & 10 & 19.2 & $0.36(-0.5$ & & \\
\hline al. [33] & $12.8 \pm 5.5$ & 15 & $7.5 \pm 9.5$ & 15 & 27 & $0.66(-0$. & & \\
\hline & $5.0 \pm 2.5$ & 30 & $4 \pm 2$ & 26 & 53.2 & $0.43(-0.10$ to 0 & & \\
\hline Subtotal $(95 \% \mathrm{Cl})$ & - & 55 & - & 51 & 100.0 & $0.48(0.09$ to 0.87$)$ & & \\
\hline \multicolumn{9}{|c|}{ Additional RT: Chronic ${ }^{\S}$} \\
\hline & $1.11 \pm 5.05$ & 25 & $-1.06 \pm 5.2$ & 27 & 100 & 0.42 & & \\
\hline Subtotal $(95 \% \mathrm{Cl})$ & - & 25 & - & 27 & 100.0 & $0.42(-0.13$ to 0.97$)$ & & \\
\hline \multicolumn{7}{|c|}{ 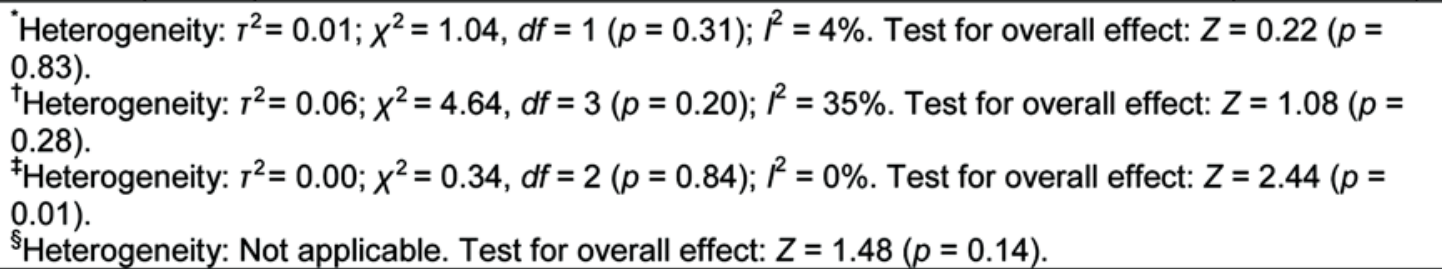 } & $\begin{array}{cc}-1 & -0.5 \\
\text { Favors } \mathrm{CT}\end{array}$ & $\begin{array}{ccc}0 & 0.5 & 1 \\
& \text { Favors }\end{array}$ \\
\hline
\end{tabular}

Figure 3.

Detailed meta-analysis of changes in Fugl-Meyer score between robot-assisted therapy (RT) and conventional therapy (CT). Four subgroups based on stroke stage of participants and comparability of duration/intensity of RT and CT were formed. Cl = confidence interval, $\mathrm{SD}=$ standard deviation, $\mathrm{SMD}=$ standardized mean difference.

\section{Motor Power Scale Meta-Analysis}

Five studies used the MPS as one of the outcome measures. Two studies focused on strength in four proximal muscles of the paretic arm by assessing power in the elbow flexor and extensor (biceps and triceps) and shoulder flexor and abductor (anterior and lateral deltoid) muscles, with a maximum score of 20 [27,37]. However, three studies used the MPS to assess 14 movements at the scapular, shoulder, and elbow joints, with a maximum score of 70 [31,35-36]. Therefore, it was not possible to combine these two measurements in one group and two separate subgroups were formed. Fortunately, all the studies in the subgroup "MPS out of 20" looked at the effectiveness of additional RT and all the studies in the subgroup "MPS out of 70" were of the same duration/ intensity for the RT and CT groups. Figure $\mathbf{5}$ shows the results of this data pooling. The mean difference has been used as the measures are the same in each subgroup. The results show that with additional RT, the gains in the MPS for 4 movements (out of 20) were significantly higher than with CT. However, no significant difference in MPS gains existed for 14 movements (out of 70) between same duration/intensity RT and CT.

\section{Motor Status Scale Meta-Analysis}

Four studies used the MSS as one of the outcome measures. One study measured MSS Synergy [31], while the other three measured MSS Shoulder/Elbow score and therefore the data could be pooled [27,35,37]. However, two of these studies $[27,37]$ were additional RT and the other study [35] was same duration/intensity. Therefore, only the two additional RT studies $[27,37]$ were pooled together in this meta-analysis (Figure 6). The results showed significant improvements in the MSS Proximal score in the RT group compared with the CT group when additional RT was employed. The single study with matched duration/intensity of RT and CT reported that the gain in the MSS Proximal score was not statistically significantly different [35]. 
JRRD, Volume 49, Number 4, 2012

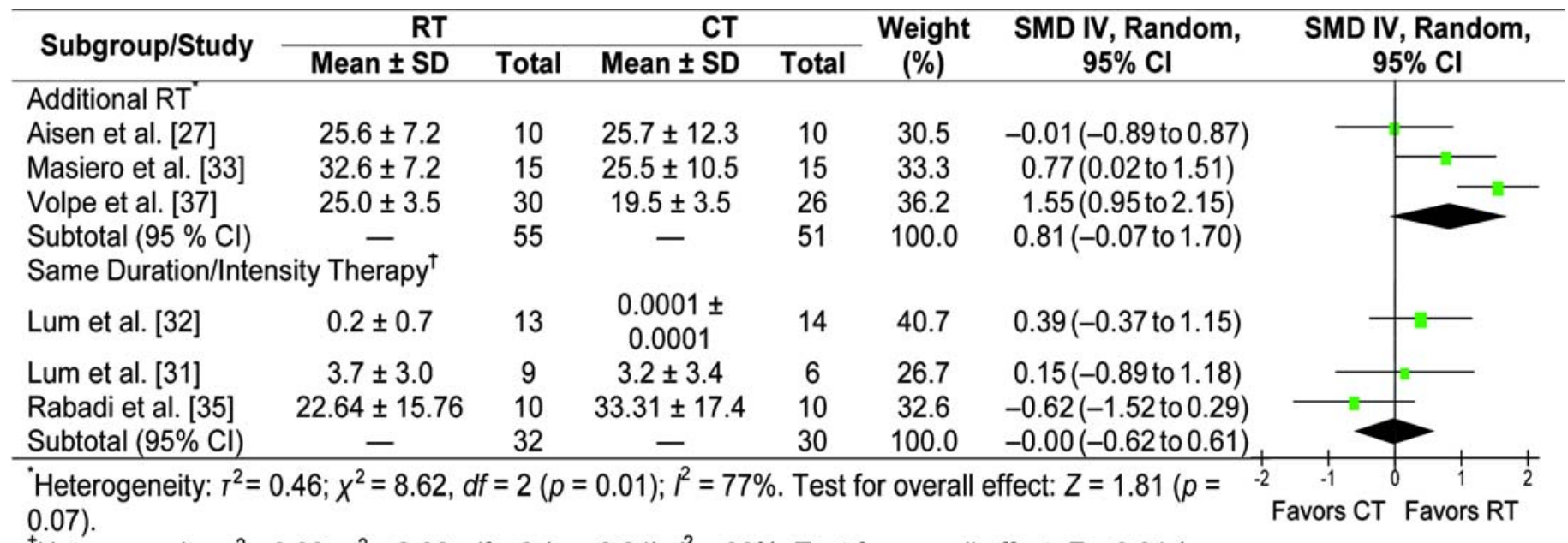

${ }^{\dagger}$ Heterogeneity: $\tau^{2}=0.09 ; X^{2}=2.86, d f=2(p=0.24) ; l^{2}=30 \%$. Test for overall effect: $Z=0.01(p=$ $0.99)$.

Figure 4.

Meta-analysis of changes in Functional Independence Measure score between robot-assisted therapy (RT) and conventional therapy $(\mathrm{CT})$ groups. $\mathrm{Cl}=$ confidence interval, $\mathrm{SD}=$ standard deviation, $\mathrm{SMD}=$ standardized mean difference.

\begin{tabular}{|c|c|c|c|c|c|c|c|c|}
\hline Subgroup/Study & \multicolumn{2}{|l|}{ RT } & \multicolumn{2}{|l|}{ CT } & $\begin{array}{l}\text { Weight } \\
(\%)\end{array}$ & $\begin{array}{c}\text { SMD IV, Random, } \\
95 \% \mathrm{Cl}\end{array}$ & \multicolumn{2}{|c|}{$\begin{array}{c}\text { SMD IV, Random, } \\
95 \% \mathrm{Cl}\end{array}$} \\
\hline \multicolumn{9}{|c|}{ Additional RT: MPS (out of 20$)^{*}$} \\
\hline Aisen et al. [27] & $3.88 \pm 2.89$ & 10 & $2.3 \pm 2.5$ & 10 & 10.9 & $1.58(-0.77$ to 3.93$)$ & & \\
\hline Volpe et al. [37] & $4.1 \pm 1.4$ & 30 & $1.7 \pm 1.7$ & 26 & 89.1 & 2.40 (1.58 to 3.22$)$ & & 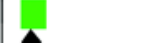 \\
\hline Subtotal $(95 \% \mathrm{Cl})$ & - & 40 & - & 36 & 100.0 & 2.31 (1.53 to 3.09 ) & & \\
\hline \multicolumn{9}{|c|}{ Same Duration/Intensity Therapy: MPS (out of 70$)^{\dagger}$} \\
\hline Lum et al. [31] & $10.1 \pm 7.2$ & 9 & $9.3 \pm 3.2$ & 6 & 57.8 & $0.80(-4.55$ to 6.15$)$ & & \\
\hline Rabadi et al. [35] & $9.53 \pm 9.01$ & 10 & $6.34 \pm 9.76$ & 10 & 24.4 & $3.19(-5.04$ to 11.42$)$ & & \\
\hline Volpe et al. [36] & $6.0 \pm 13.6$ & 11 & $6.17 \pm 8.54$ & 10 & 17.8 & $-0.17(-9.79$ to 9.45$)$ & & \\
\hline Subtotal $(95 \% \mathrm{Cl})$ & - & 30 & - & 26 & 100.0 & $1.21(-2.86$ to 5.27$)$ & & \\
\hline
\end{tabular}

${ }^{\dagger}$ Heterogeneity: $r^{2}=0.00 ; X^{2}=0.32, d f=2(p=0.85) ; l^{2}=0 \%$. Test for overall effect: $Z=0.58(p=$ $0.56)$.

\section{Figure 5.}

Meta-analysis of changes in Motor Power Scale (MPS) score between robot-assisted therapy (RT) and conventional therapy (CT) groups. $\mathrm{Cl}=$ confidence interval, $\mathrm{SD}=$ standard deviation, $\mathrm{SMD}=$ standardized mean difference.

\section{Follow-up Meta-Analysis}

In the analysis of the follow-up data, only the F-M measure was of interest to this review. Seven studies reported long-term follow-up data after the end of study. Four of the RCTs $[29,31-32,34]$ measured the F-M score at 6 months posttreatment. The other studies measured the follow-up data after 3 months, 8 months, and 3 years $[26,33,36]$. For data pooling, we selected only five studies with 6 to 8 month posttreatment data. Similar to the previous meta-analyses, the comparability of duration/ intensity between RT and CT was considered. Four of the studies had the same duration/intensity and included a 6 month follow-up, while only one had additional RT and measured the follow-up at 8-months posttreatment. Figure 7 shows the results of this meta-analysis. The results reveal that the F-M gains in RT groups were not significantly higher when compared with the matched duration/intensity CT groups. The single study [33] with additional RT reported that the difference in F-M gains at 


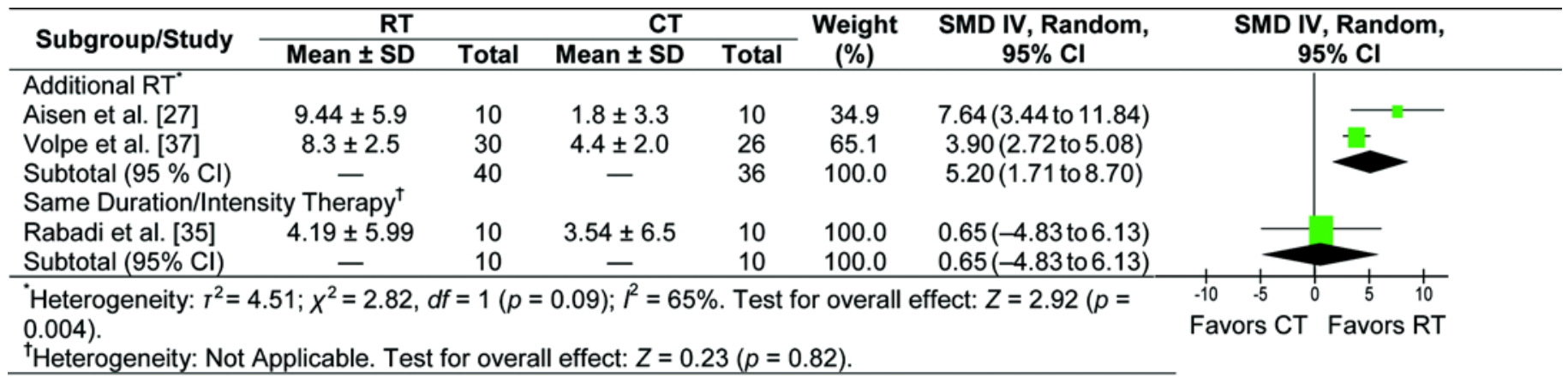

Figure 6.

Meta-analysis of changes in Motor Status Scale score between robot-assisted therapy (RT) and conventional therapy (CT) groups. $\mathrm{Cl}=$ confidence interval, $\mathrm{SD}=$ standard deviation, $\mathrm{SMD}=$ standardized mean difference.

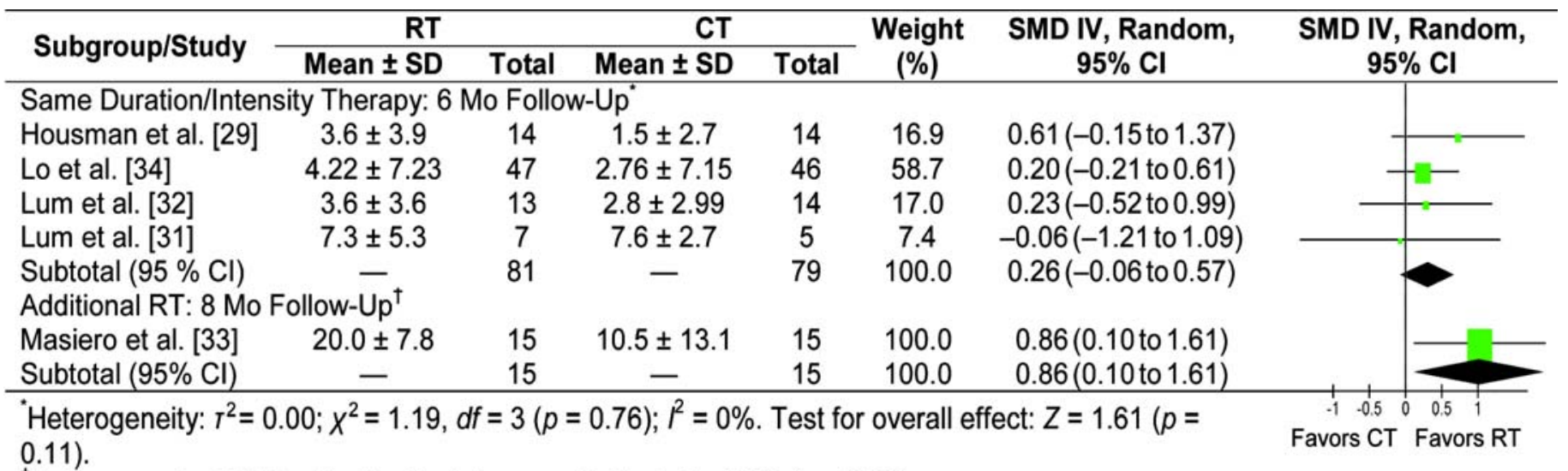

${ }^{\dagger}$ Heterogeneity: Not Applicable. Test for overall effect: $Z=2.23(p=0.03)$.

\section{Figure 7.}

Meta-analysis of changes in Fugl-Meyer score between robot-assisted therapy (RT) and conventional therapy (CT) groups at 6- to 8month follow-up. $\mathrm{Cl}=$ confidence interval, $\mathrm{SD}=$ standard deviation, $\mathrm{SMD}=$ standardized mean difference.

8 months follow-up between the RT and CT groups was statistically higher following RT.

\section{DISCUSSION}

In this systematic review, the effect of RT in comparison with CT on improving motor recovery and functional abilities of the paretic UL of people with stroke was investigated through the use of several meta-analyses. The scope of this review is limited and does not include social robots. In summary, based on the high quality RCTs, the results suggest that when the duration/intensity of conventional rehabilitative care was matched with that of RT, no statistically significant difference existed in the F-M scores between the two groups. However, when RT techniques were applied in addition to CT, they significantly improved F-M scores after treatment compared with standard CT. The extra therapeutic duration/intensity may be the reason for this result; the high number of repetitive movements generated during RT is probably the key reason for this therapeutic effect.

The meta-analysis of the changes in F-M scores based on stroke stage indicated that, similar to what was discussed previously regarding when duration/intensity of CT was matched with that of RT, no statistically significant difference existed in motor recovery between CT and RT groups in both acute/subacute and chronic stages of stroke. However, when RT techniques were applied in addition to CT during the acute/subacute stage, significantly 
improved motor recovery occurred. As only one RCT [34] examined the effect of additional RT during the chronic stage of stroke, no meta-analysis could be performed and no conclusion could be drawn.

The meta-analysis of the 6 month follow-up of the F-M changes also shows that, in that case, no statistically significant difference existed in motor recovery between matched duration/intensity CT and RT. Again, as only one study examined the long-term effect of additional RT, no meta-analysis could be performed and no conclusion could be drawn [33]. Similar to the previous results, the gains in strength, measured by the MPS, were not different between CT and RT groups when the duration/ intensity of the therapies was matched and were different when additional RT was administered. Similar results were found for gains in motor control, measured by the MSS.

The F-M score used in these meta-analyses was either from the UL section or proximal UL (shoulder and elbow) section. Based on the studies that used F-M assessment at the distal level, no significant difference existed between the RT and CT groups in terms of change in F-M Distal subscore (wrist and hand level) [31-33,35-37]. As a result, all the improvements in the F-M score from additional RT could be attributed to the proximal UL. The possible explanation for this difference is that almost none of the robotic devices discussed in this review were designed for motor improvements of the distal UL. The therapeutic program in these studies mostly focused on the shoulder and elbow of the participants with stroke. In other words, the improvements were training specific. Likewise, the gains in both the MPS and MSS measures with additional RT were also in the proximal UL.

With regards to functional abilities (measured by the FIM), the performance of the RT groups was not different than the CT groups in both matched duration/intensity and additional RT groups. This can be explained by the fact that the focus of the RT programs was mainly on recovery of motor rather than functional abilities of the UL. Another important issue is the effect of bimanual RT in motor recovery after stroke. Only one RCT [31] investigated this factor and reported that the combined unimanual and bimanual RT program had greater gains in proximal F-M when compared with CT. Lack of RCTs dealing with this issue is evident.

All of the findings demonstrate that the effectiveness of rehabilitation robotics is similar to matched CT. It is worthwhile to clarify that when the duration/intensity of conventional rehabilitative care is matched with that of $\mathrm{RT}$, this CT program is not the same as regular, standard care; it is an intensive CT program. Therefore, even though RT does not seem to lead to higher gains in UL function when matched with the same amount of extra CT (intensive CT), employing RT in clinical settings can be justified for several reasons. For instance, during intensive $\mathrm{CT}$, the therapist might not be able to deliver the intensive program as planned and might not adjust it appropriately based on the patient's progress. This can be due to fatigue or other human-related factors. On the other hand, robots always deliver the therapeutic programs as planned and are programmed to self-adjust based on the patient's progress. The repetitive nature of therapy can be delegated to a properly designed RT program, which delivers high-intensity therapeutic tasks and a "highly reproducible motor learning experience" [39]. Another reason is that RT seems more interesting and motivating to patients with stroke than $\mathrm{CT}$, which might increase collaboration, motivation, and effort by the patients with stroke in RT sessions. In other words, even though RT and intensive CT may be equivalent in terms of functional gains, combining the two may lead to increased variety of therapeutic modalities for patients. Last, but not least, there may be financial benefits when employing therapeutic robots in the long-term. For example, one therapist can setup therapeutic programs for several patients and monitor them at the same time. Nonetheless, there are limitations to the use of RT. For example, most robotic devices discussed here are planar robots (two-dimensional); they are mainly designed for shoulder and elbow movements and do not include wrist and prehension, which are frequently affected in stroke. In addition, the RT exercises are more motor-rehabilitation based techniques than function-based therapy. Furthermore, the "assist as needed" protocol that is used in many rehabilitation robotics studies may encourage patients to wait until the robot does the task for them.

In general, depending on the stage of recovery, highly intense therapy either by a therapist or a robotic device is associated with higher recovery rate [14-16]. However, patients in general receive limited therapy from therapists in rehabilitation settings [43-44] because of resource constraints. Thus, rehabilitation robotics fills this gap by providing the opportunity for more intense practice with minimal supervision by the therapist [19]. 


\section{CONCLUSIONS}

This systematic review confirms that when the duration/intensity of CT is matched with RT, there is no difference between RT and (intensive) CT groups in terms of motor recovery, ADL, strength, and motor control. Nonetheless, similar to the results obtained employing intensive CT, additional sessions of RT promote better motor recovery in the UL of patients with stroke when compared with standard CT. In other words, the use of robotics by itself does not translate into better therapy for people with stroke. Rather, robots deliver highly repetitive therapeutic tasks with minimal supervision of a therapist and these additional sessions of RT improve motor recovery of the hemiparetic shoulder and elbow of patients with stroke. Developing new function-based RT protocols, building robotic devices for rehabilitation of prehension and with more degrees of freedom, and conducting new RCTs that consider the factors discussed in this review are recommended for future studies.

\section{ACKNOWLEDGMENTS}

\section{Author Contributions:}

Study concept and design: N. Norouzi-Gheidari.

Acquisition of data: N. Norouzi-Gheidari, P. S. Archambault.

Analysis and interpretation of data: N. Norouzi-Gheidari.

Drafting of manuscript: N. Norouzi-Gheidari.

Critical revision of manuscript for important intellectual content:

N. Norouzi-Gheidari, P. S. Archambault, J. Fung.

Statistical analysis: N. Norouzi-Gheidari.

Obtained funding: J. Fung, P. S. Archambault.

Administrative, technical, or material support: J. Fung,

P. S. Archambault.

Study supervision: P. S. Archambault, J. Fung.

Financial Disclosures: The authors have declared that no competing interests exist.

Funding/Support: This material was based on work supported by the Canadian Institutes of Health Research (Emerging Team grant: RMC229260 SensoriMotor Rehabilitation Research Team).

Additional Contributions: We would like to thank Ms. Claire Fritzi Perez for review of this manuscript.

\section{REFERENCES}

1. World Health Organization. Stroke, cerebrovascular accident [Internet]. Geneva (Switzerland): WHO; 2010 [cited 2010 Aug 25]. Available from:

http://www.who.int/topics/cerebrovascular accident/en/
2. Carolei A, Sacco S, De Santis F, Marini C. Epidemiology of stroke. Clin Exp Hypertens. 2002;24(7-8):479-83.

[PMID:12450222]

http://dx.doi.org/10.1081/CEH-120015323

3. World Health Organization. The global burden of disease: 2004 update [Internet]. Geneva (Switzerland): WHO; 2010 [cited 2010 Aug 25]. Available from:

http://www.who.int/healthinfo/global burden disease/ 2004 report update/en/index.html

4. American Heart Association. Heart disease and stroke statistics - 2009 Update (At-a-Glance Version) [Internet]. Dallas (TX): American Heart Association; 2009 [cited 2010 Aug 25]. Available from: http://www.americanheart.org/downloadable/heart/1240250946756LS1982\%20Heart\%20and\%20Stroke\%20Update.042009.pdf

5. Lloyd-Jones D, Adams RJ, Brown TM, Carnethon M, Dai S, De Simone G, Ferguson TB, Ford E, Furie K, Gillespie C, Go A, Greenlund K, Haase N, Hailpern S, Ho PM, Howard V, Kissela B, Kittner S, Lackland D, Lisabeth L, Marelli A, McDermott MM, Meigs J, Mozaffarian D, Mussolino M, Nichol G, Roger VL, Rosamond W, Sacco R, Sorlie P, Roger VL, Thom T, Wasserthiel-Smoller S, Wong ND, Wylie-Rosett J; Writing Group Members; American Heart Association Statistics Committee and Stroke Statistics Subcommittee. Heart disease and stroke statistics2010 update: a report from the American Heart Association. Circulation. 2010;121(7):e46-215. [PMID:20019324] http://dx.doi.org/10.1161/CIRCULATIONAHA.109.192667

6. Heart \& Stroke Foundation. Tracking Heart Disease and Stroke in Canada [Internet]. Ottawa (Canada): Heart and Stroke Foundation; 2009 June [cited 2010 Aug 25]. Available from: http://www.heartandstroke.com/site/c.ikIQLcMWJtE/b.3483991/k.34A8/Statistics.htm

7. Kwakkel G, Kollen BJ, van der Grond J, Prevo AJ. Probability of regaining dexterity in the flaccid upper limb: impact of severity of paresis and time since onset in acute stroke. Stroke. 2003;34(9):2181-86. [PMID:12907818] http://dx.doi.org/10.1161/01.STR.0000087172.16305.CD

8. Prange GB, Jannink MJ, Stienen AH, van der Kooij H, Ijzerman MJ, Hermens HJ. Influence of gravity compensation on muscle activation patterns during different temporal phases of arm movements of stroke patients. Neurorehabil Neural Repair. 2009;23(5):478-85. [PMID:19190089] http://dx.doi.org/10.1177/1545968308328720

9. Wade DT, Hewer RL. Motor loss and swallowing difficulty after stroke: frequency, recovery, and prognosis. Acta Neurol Scand. 1987;76(1):50-54. [PMID:3630644] http://dx.doi.org/10.1111/j.1600-0404.1987.tb03543.x

10. Nakayama H, Jørgensen HS, Raaschou HO, Olsen TS. Recovery of upper extremity function in stroke patients: the Copenhagen Stroke Study. Arch Phys Med Rehabil. 
1994;75(4):394-98. [PMID:8172497]

http://dx.doi.org/10.1016/0003-9993(94)90161-9

11. Jørgensen HS, Nakayama H, Raaschou HO, Vive-Larsen J, Støier M, Olsen TS. Outcome and time course of recovery in stroke. Part I: Outcome. The Copenhagen Stroke Study. Arch Phys Med Rehabil. 1995;76(5):399-405.

[PMID:7741608]

http://dx.doi.org/10.1016/S0003-9993(95)80567-2

12. Wade DT, Langton-Hewer R, Wood VA, Skilbeck CE, Ismail HM. The hemiplegic arm after stroke: measurement and recovery. J Neurol Neurosurg Psychiatry. 1983;46(6): 521-24. [PMID:6875585] http://dx.doi.org/10.1136/jnnp.46.6.521

13. Fasoli SE, Krebs HI, Stein J, Frontera WR, Hogan N. Effects of robotic therapy on motor impairment and recovery in chronic stroke. Arch Phys Med Rehabil. 2003;84(4): 477-82. [PMID:12690583] http://dx.doi.org/10.1053/apmr.2003.50110

14. Kwakkel G. Impact of intensity of practice after stroke: issues for consideration. Disabil Rehabil. 2006;28(13-14): 823-30. [PMID:16777769] http://dx.doi.org/10.1080/09638280500534861

15. Langhorne P, Wagenaar R, Partridge C. Physiotherapy after stroke: more is better? Physiother Res Int. 1996;1(2):75-88. [PMID:9238725]

16. Huang HC, Chung KC, Lai DC, Sung SF. The impact of timing and dose of rehabilitation delivery on functional recovery of stroke patients. J Chin Med Assoc. 2009;72(5): 257-64. [PMID:19467949] http://dx.doi.org/10.1016/S1726-4901(09)70066-8

17. Nef T, Quinter G, Müller R, Riener R. Effects of arm training with the robotic device ARMin I in chronic stroke: three single cases. Neurodegener Dis. 2009;6(5-6):240-51. [PMID:19940461] http://dx.doi.org/10.1159/000262444

18. Hidler J, Nichols D, Pelliccio M, Brady K. Advances in the understanding and treatment of stroke impairment using robotic devices. Top Stroke Rehabil. 2005;12(2):22-35. [PMID:15940582] http://dx.doi.org/10.1310/RYT5-62N4-CTVX-8JTE

19. Dobkin BH. Strategies for stroke rehabilitation. Lancet Neurol. 2004;3(9):528-36. [PMID:15324721] http://dx.doi.org/10.1016/S1474-4422(04)00851-8

20. Kwakkel G, Kollen BJ, Krebs HI. Effects of robot-assisted therapy on upper limb recovery after stroke: a systematic review. Neurorehabil Neural Repair. 2008;22(2):111-21. [PMID:17876068] http://dx.doi.org/10.1177/1545968307305457

21. Oxman AD, Sackett DL, Guyatt GH; The Evidence-Based Medicine Working Group. Users' guides to the medical literature. I. How to get started. JAMA. 1993;270(17):2093-95.
[PMID:8411577]

http://dx.doi.org/10.1001/jama.1993.03510170083036

22. Physiotherapy Evidence Database. PEDro Scale [Internet]. Camperdown (Australia): The George Institute for Global Health; 1999 [cited 2010 Jul 27]. Available from: http://www.pedro.org.au/english/downloads/pedro-scale/

23. Fugl-Meyer AR, Jääskö L, Leyman I, Olsson S, Steglind S. The post-stroke hemiplegic patient. 1. a method for evaluation of physical performance. Scand J Rehabil Med. 1975;7(1): 13-31. [PMID:1135616]

24. Gladstone DJ, Danells CJ, Black SE. The fugl-meyer assessment of motor recovery after stroke: a critical review of its measurement properties. Neurorehabil Neural Repair. 2002;16(3):232-40. [PMID:12234086] http://dx.doi.org/10.1177/154596802401105171

25. Keith RA, Granger CV, Hamilton BB, Sherwin FS. The functional independence measure: a new tool for rehabilitation. Adv Clin Rehabil. 1987;1:6-18. [PMID:3503663]

26. Volpe BT, Krebs HI, Hogan N, Edelsteinn L, Diels CM, Aisen ML. Robot training enhanced motor outcome in patients with stroke maintained over 3 years. Neurology. 1999;53(8):1874-76. [PMID:10563646]

27. Aisen ML, Krebs HI, Hogan N, McDowell F, Volpe BT. The effect of robot-assisted therapy and rehabilitative training on motor recovery following stroke. Arch Neurol. 1997;54(4):443-46. [PMID:9109746] http://dx.doi.org/10.1001/archneur.1997.00550160075019

28. Fazekas G, Horvath M, Troznai T, Toth A. Robot-mediated upper limb physiotherapy for patients with spastic hemiparesis: a preliminary study. J Rehabil Med. 2007;39(7): 580-82. [Stiftelsen Rehabiliteringsinformation]. [PMID:17724559] http://dx.doi.org/10.2340/16501977-0087

29. Housman SJ, Scott KM, Reinkensmeyer DJ. A randomized controlled trial of gravity-supported, computer-enhanced arm exercise for individuals with severe hemiparesis. Neurorehabil Neural Repair. 2009;23(5):505-14.

[PMID:19237734]

http://dx.doi.org/10.1177/1545968308331148

30. Kahn LE, Zygman ML, Rymer WZ, Reinkensmeyer DJ. Robot-assisted reaching exercise promotes arm movement recovery in chronic hemiparetic stroke: a randomized controlled pilot study. J Neuroeng Rehabil. 2006;3(1):12. [PMID:16790067] http://dx.doi.org/10.1186/1743-0003-3-12

31. Lum PS, Burgar CG, Van der Loos M, Shor PC, Majmundar M, Yap R. MIME robotic device for upperlimb neurorehabilitation in subacute stroke subjects: A follow-up study. J Rehabil Res Dev. 2006;43(5):631-42. [PMID:17123204] http://dx.doi.org/10.1682/JRRD.2005.02.0044 
32. Lum PS, Burgar CG, Shor PC, Majmundar M, Van der Loos M. Robot-assisted movement training compared with conventional therapy techniques for the rehabilitation of upper-limb motor function after stroke. Arch Phys Med Rehabil. 2002;83(7):952-59. [PMID:12098155] http://dx.doi.org/10.1053/apmr.2001.33101

33. Masiero S, Celia A, Rosati G, Armani M. Robotic-assisted rehabilitation of the upper limb after acute stroke. Arch Phys Med Rehabil. 2007;88(2):142-49. [PMID:17270510] http://dx.doi.org/10.1016/j.apmr.2006.10.032

34. Lo AC, Guarino PD, Richards LG, Haselkorn JK, Wittenberg GF, Federman DG, Ringer RJ, Wagner TH, Krebs HI, Volpe BT, Bever CT Jr, Bravata DM, Duncan PW, Corn BH, Maffucci AD, Nadeau SE, Conroy SS, Powell JM, Huang GD, Peduzzi P. Robot-assisted therapy for longterm upper-limb impairment after stroke. N Engl J Med. 2010;362(19):1772-83. [PMID:20400552] http://dx.doi.org/10.1056/NEJMoa0911341

35. Rabadi MH, Galgano M, Lynch D, Akerman M, Lesser M, Volpe BT. A pilot study of activity-based therapy in the arm motor recovery post stroke: a randomized controlled trial. Clin Rehabil. 2008;22(12):1071-82.

[PMID:19052246] http://dx.doi.org/10.1177/0269215508095358

36. Volpe BT, Lynch D, Rykman-Berland A, Ferraro M, Galgano $\mathrm{M}$, Hogan N, Krebs HI. Intensive sensorimotor arm training mediated by therapist or robot improves hemiparesis in patients with chronic stroke. Neurorehabil Neural Repair. 2008;22(3):305-10. [PMID:18184932]

http://dx.doi.org/10.1177/1545968307311102

37. Volpe BT, Krebs HI, Hogan N, Edelstein OTR L, Diels C, Aisen M. A novel approach to stroke rehabilitation: robotaided sensorimotor stimulation. Neurology. 2000;54(10): 1938-44. [PMID:10822433]

38. Krebs HI, Hogan N, Aisen ML, Volpe BT. Robot-aided neurorehabilitation. IEEE Trans Rehabil Eng. 1998;6(1): 75-87. [PMID:9535526] http://dx.doi.org/10.1109/86.662623

39. Charles SK, Krebs HI, Volpe BT, Lynch D, Hogan N. Wrist rehabilitation following stroke: initial clinical results. Proceedings of the 2005 ICORR 9th International Conference on Rehabilitation Robotics; 28 Jun-1 Jul 2005; New York (NY): IEEE; 2005. p. 13-16.
40. Kahn LE, Zygman ML, Rymer WZ, Reinkensmeyer DJ. Effect of robot-assisted and unassisted exercise on functional reaching in chronic hemiparesis. Proceedings of the Engineering in Medicine and Biology Society, 2001 Proceedings of the 23rd Annual International Conference of the IEEE; 2001; New York (NY): IEEE; 2001. p. 1344-47, vol. 2.

41. Sanchez R, Reinkensmeyer D, Shah P, Liu J, Rao S, Smith R, Cramer S, Rahman T, Bobrow J. Monitoring functional arm movement for home-based therapy after stroke. Conf Proc IEEE Eng Med Biol Soc. 2004;7:4787-90. [PMID:17271381]

42. Fanin C, Gallina P, Rossi A, Zanatta U, Masiero S. Nerebot: a wire-based robot for neurorehabilitation. Proceedings of the 8th International Conference on Rehabilitation Robotics ICORR03. Daejeon, Republic of Korea; 2003. New York (NY): IEEE; 2003. p. 23-26.

43. Dewey HM, Sherry LJ, Collier JM. Stroke rehabilitation 2007: what should it be? Int J Stroke. 2007;2(3):191-200. [PMID:18705943] http://dx.doi.org/10.1111/j.1747-4949.2007.00146.x

44. Lang CE, MacDonald JR, Gnip C. Counting repetitions: an observational study of outpatient therapy for people with hemiparesis post-stroke. J Neurol Phys Ther. 2007;31(1): 3-10. [PMID:17419883]

Submitted for publication October 29, 2010. Accepted in revised form October 21, 2011.

This article and any supplementary material should be cited as follows:

Norouzi-Gheidari N, Archambault PS, Fung J. Effects of robot-assisted therapy on stroke rehabilitation in upper limbs: Systematic review and meta-analysis of the literature. J Rehabil Res Dev. 2012;49(4):479-96.

http://dx.doi.org/10.1682/JRRD.2010.10.0210

ResearcherID: Nahid Norouzi-Gheidari, MSc, OT: D-1485-2012; P. S. Archambault, PhD: F-4675-2010; Joyce Fung, PhD: D-1488-2012

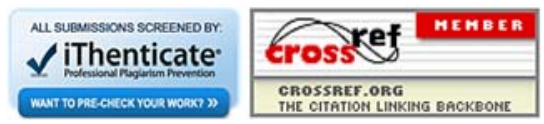


